\title{
Lapurdum
}

Euskal ikerketen aldizkaria | Revue d'études basques |

Revista de estudios vascos | Basque studies review

$8 \mid 2003$

Numéro VIII

\section{Nondik Nora euskaraz Egituren Gramatikaren eta Bateraketa Teoriaren argitan :}

Mugimendu ez-fisikoak : tipologia eta gogo-espazioen konfigurazio proposamena

Koldo J. Garai et Iraide Ibarretxe

\section{(2) OpenEdition}

\section{Journals}

Édition électronique

URL : http://journals.openedition.org/lapurdum/1100

DOI : 10.4000/lapurdum. 1100

ISSN : 1965-0655

Éditeur

IKER

Édition imprimée

Date de publication : 1 novembre 2003

Pagination : 207-231

ISBN : 9782867813436

ISSN : 1273-3830

Référence électronique

Koldo J. Garai eta Iraide Ibarretxe, « Nondik Nora euskaraz Egituren Gramatikaren eta Bateraketa Teoriaren argitan : », Lapurdum [Linean], 8 | 2003, Sarean emana----an 01 mai 2009, kontsultatu 30 avril 2019. URL : http://journals.openedition.org/lapurdum/1100; DOI : 10.4000/lapurdum. 1100 


\title{
Koldo J. Garai
}

Bordeleko Unibertsitatea

Koldo.Garai@u-bordeaux3.fr

\section{Iraide Ibarretxe}

Zaragozako Unibertsitatea

iraide@unizar.es

\section{Nondik Nora euskaraz Egituren Gramatikaren eta Bateraketa Teoriaren argitan :}

\author{
Mugimendu ez-fisikoak : \\ tipologia eta gogo-espazioen konfigurazio proposamena ${ }^{1}$
}

\section{Talmyren Hizkuntzen tipologia ereduaren oinarriak}

Badirudi mugimenduaren nozioa hizkuntza guztietan ageri dela. Hargatik, ez hizkuntzotan mugimendua adierazteko era - lexikalizatze patroiak - ez eta hizkuntza bakoitzak zein mugimendu aspektutan -- mugimendu osagaitan - jarriko dion indarra ere izango dira beti bera eta bat. Talmyren lanaren ekarririk handiena $(1985,1991,2000)$ horretara isuria da, hain juxtu : hizkuntzek arlo semantikoak eta baliabide lexikalak kidetzerakoan erakusten duten aldea edo bereiztea ikertzera, alegia. Autore horren arabera, osagai semantikoek - esangurak - eta azaleko osagaiek - hizkuntz formak - dituzten erlazio sistematikoek ez dute buruz buruko edo batean bateko korrespondentziarik hizkuntz tipoetan zehar. Izan ere, erlazio horrek itxura diferenteak har ditzake : nahiz azaleko osagai bakar batek osagai semantiko anitz adieraziko dituela; nahiz osagai semantiko bakarra

\footnotetext{
1 Lan honen bertsio goiztiarra ingelesez argitaratu zen University of South Denmark Hego Danimarkako Unibertsitatean 2002. urtean antolatu ziren jardunaldi batzuen arian : The Way We Think. Aurrerago eta landuxeago ahozko bertsio bi eman ziren : bata ingelesez Errioxako Unibertsitatean antolatutako gogo-hizkuntzalaritzako bi urteroko nazioarteko jardunaldietan, eta bestea euskaraz EHUko Donostiako Logika institutuan (ILCLin) hemen dakargun oraingo idatzizko bertsiotik gertuenak. Hiru foro horietan (behin euskaraz, bitan ingelesez) lan honi lankideek egin adin-ontzeak eskertzekoak ditugu, besteak beste Chris Sinha, Kepa Korta eta Larringan. Ibarretxek lana Eusko Jaurlaritzako Hezkuntza, Unibertsitate, eta Ikerketaren Sailaren dirulaguntzaren babesean egin ahal izan du (BFI01.429.E).
} 
azaleko osagai askotarikoek adieraziko dutela; zein - beste posibilitate hauxe ere baitago - azaleko elementu bakarra behar izanik ere, azaleko elementu horren kategoria gramatikala askotakoa izan daitekeela.

Beraz, hizkuntzek badituzte baliabide eta tresna lexikoak eta sintaktikoak, azaleko elementutzat jo genitzakeenak alde batera, eta elementu semantikoak, bestera, esanahia dakartenak; bi motatako elementu hauen arteko harremanak diferenteak dira hizkuntzaren arabera. Laburzki :

Azaleko elementuak : hizkuntzek eskaintzen dituzten baliabide eta tresna lexikoak eta sintaktikoak

Elementu semantikoak : esanahiari, kontzeptuei dagozkienak.

Laburpenarekin bukatzeko esan dezagun, azaleko elementu eta elementu semantikoen arteko erlazioak ez direla berdinak hizkuntzetan zehar, hau da, azaleko elementu bati ez dagokiola nahi eta nahiez elementu semantiko bat bakarra, ezta alderantziz ere, elementu semantiko bati azaleko elementu bat bakarrik, hots, sintaxia eta semantika elkarlanean dabiltza.

Talmyri jarraiki, arlo² semantikoak osagai semantiko txikiek osatuta daude, hau da, arlo semantiko baten kontzeptuak unitate txikiagoetan zati daitezke, osagai semantikoak esango diegunak. Osagai semantiko hauek ezin dira birzatitu, unitate semantikorik txikienak dira eta. Kontuan hartu behar da osagai semantikoak ez daudela hitz bakarrean, elementu zenbaitzuetan baino. Horrez gain, osagai semantiko denek ez dute garrantzi berdina; arlo semantiko baten osagai semantikoren bat beti izango da gainerakoak baino inportanteagoa, hain zuzen, osagai semantiko horrek arlo semantikoaren informazio nagusia eskaintzen duelako.

Horren arauz, Talmyk (1991, 2000) hizkuntzak sailkatzeko eredu bat proposatu zuen, arlo semantiko baten informazio nagusiaren edo muineko eskemaren kokapenari begira baitakioke, eta hizkuntzak bereizteko irizpidea horretantxe hartu. Bestetara jarrita ere, tipologia sailkapena azaleko elementu eta elementu semantikoen arteko erlazioetan oinarrituta dago, hau da, elementu semantikoen lexikalizatze eran datza. Behin esan, hizkuntzak sailkatzerakoan, euren ohiko lexikalizatze-bidea har daiteke kontuan, hau da, arlo semantiko baten osagai semantiko nagusiaren ohiko kokapena zein den behatu.

Ikerketa ildo horri eutsita Talmyk (1991) "sail biko tipologia" proposatuko dù : segun eta arlo semantiko zehatz baten muineko eskema zelan 
gauzatuko edo kidetuko den egitura sintaktiko eta lexikalekin ${ }^{3}$. Hala, bi motatakoak ditugu Talmyren lexikalizatze patroiok ${ }^{4}$ :

Satelite esparruko hizkuntzak (S-hizkuntzak), zeinetan informazio nagusia edo muineko eskema satelite batean kokatzen den. Talmyk satelitea honetara definituko du : "the grammatical category of any constituent other than a noun-phrase or prepositional-phrase complement that is in a sister relation to the verb root. [It] can be either a bound affix or a free word" 5 . Ohar gaitezen Talmyren ereduan, sateliteak aditzez landako osagaiak direla : hizkiak aurrizki eta atzizkiak —, morfema askeak (partikulak), baina ez direla inoiz. ere izen sintagmak edo preposizio-postposizio sintagmak.

Aditz esparruko hizkuntzak beste muturrean ditugu (A-hizkuntzak); hizkuntza hauetan, informazio nagusia aditzean kokatuko da

Mugimendu gertaeren kasuan, muineko eskema higidura da. Talmyren arabera, higidura gertaerak kokagune egonkor edo higigaitz bati eusten dioten egoerak edo euren baitan mugimendua duten egoerak izango dira (Talmy 1985 : 85), hots, mugimenduaren ekintzak zein puntu higigaitzean geldierak dauzkaten egoerak. Zelaiago emanda : leku batetik bestera mugitze egoera, lekuan bertan mugitze egoera, eta mugimenduaren ondorengo geldiera.

Egoerok, noski, oinarrizko osagarri semantikoen araberako multzoka azter daitezke. Osagarri horiek bi eratakoak izan daitezke : barruko osagaiak - Irudia, Hondokoa, Bidea eta Higidura - eta kanpoko osagai gerta-kideak edo konkomitanteak - Modua eta Kausa - (Talmy 1985 : 61) :

\section{A/Barrukoak}

a. Irudia (Figure) : mugituz doan objektua.

b. Hondokoa edo behea edo azpikoa (Ground) : entitatea (k), zeinaren arabera irudia mugitzen ari den 6 , hau da, irudiaren mugimenduaren erreferentzia-entitatea

\footnotetext{
${ }_{3}^{3}$ Irizpide morfosintaktikoetan oinarritutako tipologia dugu berau. Talmyren aurteko lanetan ( 1972, 1985) ere, osagai semantikoek item lexikal berean bat egiten zutenentz kontuan harturik banatuko zituen munduko hizkuntzak.

${ }^{4}$ Ikus Slobin eta Hoiting (1994) sail biko tipologia honen adinontze posibleetarako.

5 Talmy $2000: 102$

6 Slobinek (1996b) berriro adimugatuko du hondoko honetara : inguru fisikoaren ezaugarria izango da, ezaugarri hori sorburu, ingurune, mugarri edo heliburu lanetan arituko delarik. SORBURUA (source) : higialdiaren hasierako lekua. HELBURUA (target) : higialdiaren bukaerako lekua. MUGARRIA (milestone) : beste helburu batzuk. INGURUA (medium) : bidearen inguruko informazioa, gainerako informazioa.
} 
C. Bidea (Path) : Irudia darraion ildoa ${ }^{7}$, hots, irudiaren ibilbidea edo kokagunea

d. Higidura (Motion) : higitze ekintza baten predikazioa bera; mugitzearen ekintza edo puntu egonkorrean geldiera.

B/Kanpokoak :

a. Modua mugitzeko eraz ari da,

b. Kausa mugimenduaren sortzeaz edo eragileaz.

Haramen adibide batzuk euskaraz :

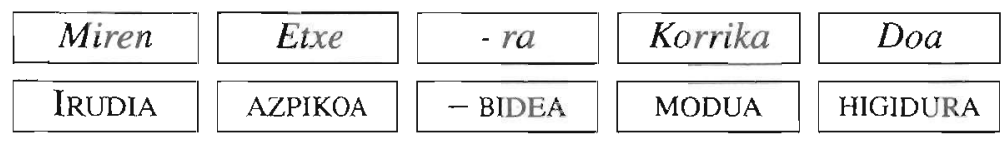

\begin{tabular}{|l|l|l|l|l|l|l|}
\hline Miren & Unibertsitate & -tik & etxe & -ra & Korrika & Doa \\
\hline IRUDIA & AZPIKOA & - BIDEA & AZPIKOA & -BIDEA & MODUA & HIGIDURA \\
\hline
\end{tabular}

\begin{tabular}{|c|c|c|c|c|}
\hline Mirenek & Bere laguna & Arbola & -tik behera & bota du \\
\hline KAUSA & IRUDIA & AZPIKOA & BIDEA & HIGIDURA \\
\hline
\end{tabular}

Guztiarekin ere, Talmyk (1985 : 487) eman zigun adibide klasikotik atera genezakeen legez, hizkuntzak ez datoz bat higiduraren osagai semantikoak kodetzerako joeretan; adibide hartan, botila azaleratu edo atera zela esateko moduak aztertu zituen Talmyk, bai ingelesez, bai espainolez :

1. The bottle floated out (botila kanpora azaleratu zen)

2. La botella salió flotando (botilak azaleratuz irten zuen)

Bion arteko lehen aldeak mugimenduaren Bidea kodetzeko eraz dihardu : espainolez mugimenduaren Bideari buruzko muineko informazioa aditzak emango duelarik (salir 'irten'), ingelesez informazio hori, ostera, 
partikula batek, edo - Talmyren berbetan — aditz sateliteak (out 'kanpora") emango digu8. Bigarren diferentzia mugimenduaren Modua adierazteko erari dagokio : ingelesak Bidea ez duenez aditz nagusian ematen, intzirrikatua aske dagoke float bezalako Modu aditzetarako. Espainolez, aldiz, aditz nagusiko zirrikitua Bide aditzek beterik baitute, mugimenduaren Modua adierazpide berezituez eman ohi da, flotando 'azaleratuz' gerundioa berbarako.

Adibideotan ikusi dugunez, A-hizkuntzetan Bideari buruzko informazioa eta Higidura aditzean bertan ageri ohi da; S-hizkuntzetan aldiz, aditzean agertzen den informazioa Higidura eta Moduari buruzkoa da. Osagai semantikoak batera emanik datozenean, konbinaketa horri bategite (conflation) esango diogu. S-hizkuntzak eta A-hizkuntzak bategite desberdinak erabiltzen dituzte. Labur batuz :

S-hizkuntzetan Higidurak eta Moduak bat egingo dute aditzean; ordea bidea satelitean emango da; hala jokatzen duten hizkuntzen adibidea ingelesa izan daiteke.

A-hizkuntzetan Higidurak eta Bideak bat egingo dute aditzean, eta Modua elementu berezi batez adieraziko da. Hizkuntza hauen ordezkaria espainola izan daiteke.

\subsection{Talmyren tipologia eta euskara}

Talmyren tipologiaren arabera, esan dezagun euskara A-hizkuntzen tankerakoa dela, hau da, espainolaren taldekoa dela, higialdia emateko era arruntagatik $^{9}$, hots, Bide osagarri semantikoa aditzean ageri zaigu eta Modu osagarri semantikoa aditzetik kanpo ${ }^{10}$ :

3. eta erlauntzetik erle guztiak irten ziren hegaka [B20i]

Goiko adibideko (3) irten aditza, Bidea eta Higidura batera dakartza,

\footnotetext{
${ }^{8}$ Euskal kasurako ondo etor dakiguke ateraren etimologia, bai eta erabilera sistematikoa denean ere, adibidez postposizioetan : cf. Ubillosen honez ateranzko edo, arruntagoa nahi bada, honetaz at. "Estilo zuzentzaileek" irten iragankorra debekatu ordez (cf. OEH), hobe lukete hausnar erabiliko balute irten iragangaitz erabili uste den inguruetan zergatik dabilen hura aterarekin lehian eta, aldiz, zergatik trantsitibo darabilgunok ez dugun holako aukerarik. Gai honetan ondorio sendoetara heltzeko, gaurko maisu juanen baten intuizioa barik, corpus-linguistika erabili behar da mendebaldeko tradizioko testuetan barrena, berbarako, eta inferitu zein diren ateraren konbinatoriak erakusten dituen adiera posibleak, cf. bere burua atera zuen, atera zitzaion eta abar. Gure artikulu honek horko aztertze ildorako aztarren teorikoak eskain litzake.
}

9 Talmyk (2000:27) "arrunt" hori honetara dakar : "characteristic'as those expression which are "colloquial in style, [...], frequent in occurrence in speech, [...] and pervasive". Azpimarra geurea da.

10 Ibarretxe 2004, arg. 1, arg, 2. 
eta hegaka aditzondoarekin lagunduta dator; adberbio horrek mugimenduaren Modua adieraziko du gertaera honetan. Alabaina, A-hizkuntzen tankerakoa izanagatik ere, euskarak baditu zenbait berezitasun aipatu taldekoekiko, zeren euskaraz Bide osagaiaren deskribapena zehatzago eta maizago egiten baita beste A-hizkuntza batzuekin erkatuz gero.

Euskararen berezitasun hori Slobinen Bide osagaiaren deskribapen hipotesiaren kontra doa erabat ${ }^{11}$. Autoren honi jarraiki, A- eta S-hizkuntzek ez dituzte era berean Bide eta Hondoko osagaiak maneiatzen hizkuntzak duen muineko eskemaren ondorioz. Desberdintasun nagusia hauxe da : S-hizkuntzetako bi osagai hauen deskribapenak A-hizkuntzetakoak baino aberatsagoak, luzeagoak eta gainera, maizago egiten direla. Hala da ezen, ingelesezko higidura gertaeretan adibidez, ia inoiz ez dela aditza biluzik agertuko - " "The boy fell" —, aitzitik, ia beti hainbat Bide eta Hondoko osagairekin ageri beharrean aurkituko dela - "The boy fell down from the cliff into the river" - Gaztelaniazko higidura gertaeretan, berriz, alderantzizko joera ikusten da; aditza soilik erabiltzen da sarritan - "El niño se cayó —, eta Bide eta Hondoko osagai semantikoekin agertuko balitz, osagaia bat bakarra izango litzateke berau — "El niño se cayó al río" -

Euskarazkoetan aurkitzen duguna beste hauxe da : aditza ia beti Bide eta Hondoko osagai semantiko bat edo gehiagorekin agertzen ahal zaigula, batez ere, Sorburua eta Helburua batera ; eta horrixe deitu diogu "bide osoaren egitura", adibidez: "Umea amildegitik behera erori zen ibaira". Eman ditzagun zenbait argibide Frog Stories narrazioetatiko ${ }^{12}$ higidura gertaeraz (Slobin 1996 eta Ibarretxe-Antuñano 2004) :

\begin{tabular}{|c|c|c|c|}
\hline & Aditza soilik & Aditza+Bide/Hondoko & Bide/Hondoko osagai kopurua \\
\hline Euskara & $\% 11$ & $\% 88$ & Bat baino gehiago $\rightarrow$ Bide osoa \\
\hline Ingelesa & $\% 18$ & $\% 82$ & Bat baino gehiago \\
\hline Gaztelania & $\% 37$ & $\% 63$ & Bat bakarrik \\
\hline
\end{tabular}

\footnotetext{
11 Ikus Slobin 1996.

12 "Frog Stories" edo 'Igelaren kontakizunak'etiketa orokor bat da, tresna berarekin baina hizkuntza diferenteetan eragindako kontaerez eraikitako datu-korpusa izendatzeko. Lanabes hori Mayerren (1969) Frog, where are you hitz gabeko irudi liburuak eman zuen; liburuak mutiko baten istorioa kontatzen du, txakurraz lagundurik bere igelaren bila abiatu den mutikoarena. Liburu hau ikerlari askok erabili izan dute zabal eta luze askotariko helburuetarako (ikus Bergaman eta Slobin 1994, datuak biltzeko jardunbideez) hizkuntza anitzetan datuak eragiteko.
} 
Taulan ikus dezakegunez, euskara, Bide osagaiari dagokionez, S-hizkuntzen taldean koka daiteke. Sarritan sorburua eta helburua aditz bakarrekin agertzen dira eta hori, euskararen ezaugarria da. Hurrengo atalean, bide osoaren egituraz jardungo dugu.

\subsection{Bide Osoaren Egitura (BOE)}

Bide Osoaren egituraren definizio bat aurrera dezagun orain : 'higialdi bateko sorburu eta helburuak, bi-biak eta batera agertzeko joera'(Ibarretxe arg. 2). Adibidez :

\section{Bat-batean Txuri txakurra leihotik behera joan zen}

\section{Goio arroka artetik behera jaitsi zen}

\section{Pasillo ospeletik barrura sartuko zarete ilunetan}

Hauxe genuke adibideotako ezaugarririk nabarmenena : sorburu eta helburuen arteko tartean jartzen dela arreta, eta ez sorburuan edota helburuan; bestela esanda, sorburuak, helburuak eta euren arteko tarteak unitate gestaltikoa eratuko dute. Gainera, Golbergi (1995), Fillmoreri eta Kayri (1995) jarraiki, haramen 'egitura'izateko harako unitate batek behar dituen ezaugarriak : egiturak berak esanahia dakar (BIDE HESITUA), eta esanahi hori ezin da atera konposizionalitatearen bidez.

Bide Osoaren egitura Bidea kontzeptualki hesiturik dagoenean erabiliko da, hau da, sorburuko egoera eta helmugakoa espazioko puntu lotutzat hartzen direnean eta, ondorioz, euren artean dagoen distantzia (Bidea) traiektoria murriztzat eta puntu finko biok mugatu balute bezala jotzen denean.

Orain arte, BOE unitate gestaltikoa eta euskararen berezitasuna dela esan dugu. Hori baieztatzeko, Ibarretxek (2004, arg.2) bi froga aurkezten ditu : alde batetik, egitura hau bai semantikoki bai morfosintaktikoki egitura hau zatiezina da, hau da, ezin da ezelango elementurik sartu sorburu eta helmugaren artean hiztunek txartzat joko ez badute behintzat ${ }^{13}$. Bestaldetik, egitura hau ez da inoiz ere agertzen euskara bigarren hizkuntza bezala daukaten hiztunen Frog Stories narrazioetan. Lehen esan bezala.

Ora gakizkion orain gure azterketaren ekarriari. 


\section{Nondik Nora Egitura den aldetik}

Datuek erakutsi digute nondik nora alde batetik egitura dela, eta bestetik, egitura hori euskarak duen egiturarik emankorrenetakoa ${ }^{14}$ eta esamoldeetan ageri den sistematikoenetako bat dela. Izan ere, ikerketaren beste alderdi batetik esamoldeak aztertzeari eutsi genion, Zamarriparen Manual del Vascófilo hartan eman zituen "modismos vizcainos" sailkatu nahian.

Honez gero, proposa daiteke egitura joera batetik atera daitekeela; artez esateko, erabilerak joera hauxe erakutsiko lukeela : ablatiboa eta adlatiboa elkarren segidan jartzekoa; horri Ibarretxek Bide Osoaren egitura deitu izan dio, arestian esan daroagun legez. Kontura gaitezen joera honetan debekurik egon ez arren, ablatiboaren eta adlatiboaren artean ez ohi dela ostantzeko elementurik sartu, eta hori ez bakarrik esamoldea daukagunetan, ezpabere erabilera ez idiomatikoan ere. Joeratik egiturarako bidean, esamoldeen lurraldean geratuko litzateke, eta honelaxekoa izan liteke, Glucksbergen azterketari jarraiki 15 :

- Esamolde ezagunen berba osatzaileek, esamoldezko testuinguruan erabiltzearen erabiltzeaz, esamoldeak berezko dituen esangurak berenganatuko lituzkete.

- Sintagmari lotutako esangura horiek eskuratu eta gero, kontzeptu idiomatikoen osagaien arteko erlazioak mantentzen dituzten esamolde aldakiak prozesamendu linguistiko arruntaren bitartez uler daitezke.

Behin egitura ezarrita, edo berezko esangura bereganatzekotan dagoelarik, inguru ez-fisikoei ere aplikatuko litzaieke. Inguru ez-fisiko horiek denborari aplikatuko litzaizkioke, ezerri baino lehen; beharbada aplikazio hori proiekzio motarik lehenbizikoena litzatekeelarik. Alabaina, proiekzioa berez - metaforikoa izan zein analogikoa - ez da denborazkoetara mugatzen $^{16}$; alde batetik, denborazko erabileretan postposizioak kasu berezitzat hartu daitezke : Hortik aurrera, etab. Baina, bestetik, badira denborazko beste erabilera batzuk ustez korapilotsuagoak direnak : Ahotik eskura.

\footnotetext{
${ }^{14}$ Emankorra diogunean, bai egiturak duen ahalmen sortzaileari, hots, malgutasunari, bai esamoldeetan suertatzen den maiztasunari, bai beste hurbileko egiturekiko hurbiltasunari egiten diogu aipu. ${ }^{15}$ Cacciari eta Tabossi 1993

16 Proiekziorako ikus Garai (agertzear), Turner (1996) en ildotik. Edozein kasutan, oraingo horretan proiekziorik dagoenentz eta, egonez gero, metaforikoa den edo beste era batekoa aztertzeko puntua ere bagenuke.
} 
Aipa ditzagun, arin batean, erabili ditugun iturriak : Izagirre (1981), Mokoroa (1990), Zamarripa (1913) ${ }^{17}$. Iturriotarik 1440 sarrera lortu ditugu; hala ere, artikulu honetan erabilitako sarrerak 484 izan dira, ez baititugu sartu ez erakusleak (handik aurrera), ez postposizioak (sei urtetik gora) ez eta kuantifikatzaileak (batetik bestera) darakutsatenak ere.

\subsection{Bide Osoaren Egituraren hainbat erabilera}

Oraintxe berri iradoki dugun bezala, Bide Osoaren Egiturak mugimendu fisikoaz bestelako hainbat erabilera ere baditu gainera. Hemendik aurrera $\mathrm{BOEa}$ ingurune ez-fisikoetara proiektatzen denekoa aztertuko dugu. Erabil ditzagun eredu hauek hausnar :

$\begin{array}{lll}\text { 7. Belaunetik belaunera } & \Rightarrow & \text { zikloaren ideia } \\ \text { 8. Ahotik eskura } & \Rightarrow & \text { arintasuna } \\ \text { 9. Argitik ilunera } & \Rightarrow & \text { zikloa } \\ \text { 10. Hitzetik hortzera } & \Rightarrow & \text { arintasuna } \\ \text { 11. Okerretik okerrera } & \Rightarrow & \text { indartzailea } \\ \text { 12. Gezurretik gezurrera } & \Rightarrow & \text { indartzailea }\end{array}$

Ikus daitekeenez esangura askorekin agertu ohi da egitura : "belaunetik belaunera” esamoldeak zikloaren ideia dakarkigu gogora, "argitik ilunera" esaerak egiten duen legez; "ahotik eskura" bat-batekotasuna edo berezetik-hortzera" horrek emango digun bezala ; "okerretik okerrera" eta "gezurretik gezurrera" esamoldeek, biek ala biek ere, indartzaileren bat darakutsate, baina ez prefosta indarrera berdina.

Askotarikotasun semantiko honek azalpena behar du, hau da, pentsatu behar dugu ea zein den "bertatik bertara" eta "hitzetik hortzera" esamoldeek elkarrekiko duten lotura. Begiratu batera, erabilera hauek guztiek komunean daukatena BOEk emango luke; baina, guztiarekin ere, bada arazorik ere, zeren egiturak ez baitu erabat agortzen askotarikotasun semantiko horren zioa. Egituraz gain, egiturako zirrikituek ere parte hartzea izan beharko dute, eta zirrikituotan item lexikalak ditugu. Honez, zirrikituei halako azalpen-irtenbidea aitor dakieke :

Mugarrien eduki semantikoak $\Rightarrow 7,9,11,12$ ereduak azalduko lituzke

Erreduplikazioak $\Rightarrow 11,12$ ereduak azalduko lituzke

\footnotetext{
17 Eskertu behar diogu Inaki Ugartebururi Mokoroaren testua modu erabilgarrian eskura jarri zigulako; oso bilaketa mugatuak eskainiko bailizkiguke bestela HABE-Labayruk argitaraturiko CDROM bertsioak.
} 
Zirrikituak Mugarriek ${ }^{18}$ beteko dituzte, horretarako item lexikalek ematen dutena azaldu beharra dago ${ }^{19}$. Labur batuz, askotarikotasun semantiko haren aitzinean, faktore asko hartu behar dira kontuan, eta azalpena ez datza horietako bakarrean, elkarlanean baino : alde batetik BOEk berak dakarren esangura; horri jo beharko zaio egituran bertan txertatzen diren elementuen esangura lexikala, halaber askotu elementuon euron errepikapenak egiturari erants dakiokeen esangura ere bai, eta beste.

Dihardugun orain egiturako mugarrietan txertatzen diren elementu lexikalen artekoez.

\subsection{Item lexikalen artekoez}

Elementu lexikalen arteko harremanok antzekotasun vs. bestelakotasun kontzeptuetara erakar daitezkeelakoan gaude. Kontzeptuok oinarrizko metafora kontzeptual hauen arabera ulertu ohi ditugu : ANTZEKOTASUNA Gertutasuna Da eta Bestelakotasuna Distantzia Handia Da, edo bestetara : Bereiztea vs. bat etortzea. Hau da, bi kontzeptu antzekotzat baldin baditugu fisikoki gertu edo hur kokatu ohi ditugu.

Bestalde, elementu lexikalak gorputz atalak direnean, hiztunek esamoldetzat jotzea errazagoa suerta daiteke, hain zuzen ustezko "opakotasunagatik" edo gorputz atalen erabilera metaforikoa onartzera eginago gaudela$\mathrm{ko}^{20}$. Bukaeran eman ditugun adibideetan "gorputz atalak" izendatu dugu sail

18 Ikus "Mugarriaren" definizioa goragoko ohar batean.

19 Bada arrazoirik lexikoa ere egituratzat hartzeko, egitura gramatikaren azken joerak dioten legez. Bybee, Joan. 1998. The emergent lexicon. CLS 34: The Panels. 421-435. orr. University of Chicago : Chicago Linguistic Society. Hitzen gramatikaz, beste erreferentzia hauxe ere interesekoa da : Hudson, Dick. 2002-08-22. http://www.phon.ucl.ac.uk/home/dick/WG/WG4PG/WG4PG.htm. Eskuratua : 2004/03/09.

20 "Opakotasunaren" kontzeptuak anikulu teoriko oso bat merezi du. Fillmore, Kay eta O'Connor 1987 tik eman dakioke abia balizko artikulu horri, hain zuzen, opakotasuna homatzearekin lot daitekeelako, eta hormatzeak partsimoniaren kontzeptura garamatzalako; partsimoniak hizkuntza gradu diferenteetara hormatutako esamoldeen multzotzat hartzea suposatuko du, eta hortaz hizkuntza norma den aldetik kontsideratzera bultzatuko gaitu, hizkuntzan posiblea dena barik (sistema) probablea dena aztertzera (norma), alegia, maiztasunaren aldakia ere kontuan hartuta; horrek itzelezko garrantzia du hizkuntzaren irakaskuntzan (eta euskal 'linguistek'txara gehiago eman beharko liokete esparru horri, euskararen biziraupenerako kontsurnitzen den diru eta ikaste ahaleginak kontuan harturik), ikus Lewis 2001 "esamoldezkotasunaren espektroa". Bestalde Cacciari 1993 ere gogoan erabiltzea interesgarria da, batez ere metaforaren argitan ematen dituen arbitrariotasunarekiko edo hautazkotasunarekiko hausnarketengatik; hartara, esamolde baten ontogenesia motibatua (eta hortaz, sistematikoa) dela esan daiteke. Behin esan, esamoldeetatiko gramatika ez da periferikoa, ez dagokio ornatus bati; esamoldeetatiko gramatika askoz ere errealistagoa dela ondoriozta genezake. 
oso bat, hor dago Ahotik sudurrerako astirik gabe, berbarako. Gorputz atalei dagozkien behagarri zenbait idoro ditugu :

1) Edozein gorputz atal ez da egitura honetan sartzen. Gure datuetan 20 bat gorputz atal ageri dira :

- Aho, begi, bekoki, belarri, sudur, buru, gogo, esku, behatz, hatz (atzamar...), ukabil, sama (eztarri, zintzur...), idun, lepo, bizkar, golko, magal, hanka (txanka, zango...), oin, orpo, kokots, mihi (mingain...), hortz, hagin, papar, bular.

2) Zein gorputz atal sartzen den Bide Osoaren Egituran murrizturik dago. Honelako bikoteak aurki ditzakegu : ahotik sudurrera (eta alderantziz), burutik oinetara (eta alderantziz), baina honelako bikoteak ez dira ageri : *ahotik oinetara, *burutik sudurrera (baina bai gogotik mihira). Murrizketa hauek honetan dautzá : entitateok kontzeptualki lotutzăt hartzen diren ala ez.

3) Gorputz atalon arteko distantzia ez da beti berdin hartzen : Ahotik sudurrera dagoen distantzia, eta burutik oinetara dagoena ez dira berdinak, beraz, euren esangura ez da bat eta bera, nahiz eta bi-biok Bide Osoaren Egiturako partaide izan, eta nahiz eta sorburu eta helmugatzat biok ala biok ere gorputz atalak eduki.

Gorputz ataletarako ez ezen, egitura honetaz baliatzen diren adibide guztietarako zaizkigu baliagarri aipatu goiko hiru puntu haiek. Errepikapenaren arazoari egituron behineko taldeak proposatu eta gero eutsiko diogu.

\subsection{Taldekatzekoak}

Datuok sailkatu ahaleginetan, bi talde proposatuko ditugu. Lehen taldean, Sorburua eta Helburua antzekotzat hartzen dira, hau da, Sorburutik Helburura doan aldea edo distantzia laburra da; adibidez ahotik sudurrera, eta ahotik eskura. Badago hemen egin beharreko oharra ere : ahotik eskura esamoldeak badu beste erabilera metonimiako bat, zeinetan ahoa hitzezko munduaren ordezkari den, eta eskua ekintzen mundukoa; konpara bitez haiek beste honekin : esanetik eginera, hots, 'ahotik eskura'ren aldaki epistemologikoagoa eta literalagoa.

Bigarren taldean, aldiz, Sorburua eta Helburua kontzeptualki bereizitzat hartzen dira, bestela esan, Sorburutik Helburura dagoen aldeari edo distantziari luze iritziko zaio; adibidez : burutik oinetara, argitik ilunera. Hemen ere, bada egin beharreko beste ohar bat : argitik ilunera egiturak duen 
distantzia psikologikoa eskala pragmatikoek kulturan hartzen duten lekuaren araberakoa izan daiteke, hau da, baliteke honetaz eredu kulturalik deskribatu behar izatea (ikus beherago honetaz) 21 .

\subsubsection{Errepikapenaren arazoa}

Tipologia irizpiderako, elementu lexikalen arteko alde kontzeptualari bakarrik kargu hartuz gero, ez genekikeen elementu lexikal horiek bat eta bera direnean zer egin. Beraz, areago findu behar da taldekatzea.

Esan dezagun bada, talde bakoitza berriz erdibitu daitekeela, item lexikala errepikaturik dagoen ala ez begiratuta. Eta iluntzetara ere bai; nahiz eta errepikapen hau garrantzizko eta noraezeko ezaugarria den, ez da nahikoa tipologia eratzeko, hara zergatik :

\section{Argitik ilunera = argitik argira; egun osoa.}

Kontura gaitezen errepikapen lexikala dagoen arren, ez dagoela erreferentzia kidetasunik. Ekar ditzagun gogora rol-balioa dikotomia Fauconnierrek (1994) azaldu bezala; itemon artekoa rol-balioa, hots, eredu vs. adibide dikotomiara ekar daitekeenez, argitik argira kasuan argi $i_{1}$ eta $\operatorname{argi}_{2}$ terminoek egun diferenteei egingo liekete aipu. Alde teorikotik hau areago landu daiteke Fauconnier eta Turnerren (2002) ildotik; han errotiko antropozentrismo batez, gizakiak kontzeptuak manipulatu ahal izateko giza neurrietara dakartzala diote, konpresio-deskonpresio gogo jardunen bitartez. Gure kasura aplikaturik, egun ${ }_{1}$ hasi deneko argitik egun ${ }_{2}$ hasi deneko argira, zatikatuko genuke denboraren balioa edo adibide konkretua, eta gero hori maila abstraktuagora eramanik, traiektoria hori eredugarri bilakatu. Zehatzago ere Turner eta Fauconnierren (2002) Zikloaren Sarea esango diote horri (ikus beherago).

Azalpen honek beste adibideetarako ere balio digu : belaunetik belaunera, gezurretik gezurrera, okerretik okerrera, menditik mendira.

Hori guztia hala izanagatik, bada beste errepikapen mota bat ere, errepikapen indartzailea esan dioguna alegia. Okerretik okerrera eta gezur. retik gezurrera bezalakoek indartze prozesua dakarte; aldiz, belaunetik belaunera eta menditik mendira bezalakoek ez. Hona hemen gure hipotesia : belaunetik belaunera esamoldean sorburura eta helburua entitate diferente-

2i "Eredu kulturala" diogunean, Lakoff eta Tumer 1989-ren bidetik diotsogu : han, Izakiaren Katea Nagusia aztertu zuten. Ikus Garai 2002 horretaz. 
tzat jotzen diren bezala, gezurretik gezurrera esamoldean sorburuaren eta helburuaren arteko distantzia txikietsia da ea desagertzeraino 22.

\subsection{Tipologiaranzkoak laburbilduz}

Laburtza ditzagun orain arterainokoak. Tipologia egiteko parametro bi aipatu ditugu : 1) sorburutik helburura dagoen distantzia kontzeptuala eta 2) sorburu eta helburuaren roletan item lexikala errepikatzen denentz. Horrek lau talde eman dizkigu :

- Sorburutik helburura alde txikia :

- A1 Taldea : item lexikal diferentea : ahotik eskura

- A2 Taldea : item lexikal bera : gezurretik gezurrera

- Sorburutik helburura alde handia :

- B1 Taldea : item lexikal diferentea : argitik ilunera

- B2 Taldea : item lexikal bera : belaunetik belaunera

\subsection{Azken hausnarketa : eskala pragmatikoak eta eredu kulturalak}

Lehen esan dugu eredu kulturalek eta eskala pragmatikoek ere hartzen dutela esku nondik nora egituran, hau da, inguru kulturalak bere interpretazio aztarren eta langak ezarriko dituela. Har dezagun goizetik gauera bi kasu hauetan :

14. Inurria bezala goizetik gauera ari arren, doi-doian bizitzeko lain egin ezkero pozik gu (Mokoroa 89033)

15. Ameriketan izana zen, uri askotan pilotari egona, eta goizetik gauera ez dakit nola dirutua (Mokoroa 12016) 23

Behingo batean senak emango ligukeen azalpena hauxe izan liteke : kultura batean delako jarduera batek hartu behar duen edo hartu ohi duen denbora ezarrita dago ekanduz; eta hala, aldiak hori baino luzeago jotzen

22 "desagertzeraino" horrekin Langackerren nabarmentze kontuez ari gara, hau da, Profiling delakoaz.

23 Adibide guztietan ortografia gaurkotuaz eman ditugu. 
badu, gertaerari luze iritziko diogu kultura horretako partaide garenok, eta berdin iruntzetara ere ${ }^{24}$. Sofistikatuago esate arren, sorburutik helbururakoei begiratuta, sorburuak eta helburuak trinkatutako aldiaren baloreen metaketa bezala hartuko da bidea ${ }^{25}$. Bide horri hiztun komunitate batek luze iritziko dio, edo labur, gertaera horretarako kulturak ezarritako iraupen edo eskalaren neurriaren arabera. Hori guztiau kontuan hartuz, (14) adibidea B 1 taldean sar liteke, eta (15) adibidea A1 taldean.

Ondorio orokorragorik ere atera genezake hemendik, jakiteko : eredu kulturalak eta eskala pragmatikoak ez direla esperientzian oinarritutako mailakatzeetarako bakarrik aplikatzen, baita egitura gramatikaletarako ere 26 .

Hura ikusita, proposa ditzagun orain azterbide batzuk-batzuk. Demagun hauexek direla (14) eta (15) ren esangura posibleak : osotasuna vs. oso azkar. Zehatzago esateko, defektuzko esangura osotasuna litzateke, eta murrizketa kulturalek eraginda oso azkar. Hala da ze, osotasuna Bideak dakarren entitatearen Sorburu eta Helmugak mugatzat hartzetik erakarriko genukeela, eta hor nabarmentzen direnak Mugarriak direla; aldiz, Oso azkarren esangurarako Sorburua eta Helburua ez dira muga kontsideratzen, zeren nabarmentzen dena Bidea bera baita.

\section{Eredu bategile baten bila}

Aurreko atalean bi parametro aurkeztu ditugu : Sorburuaren eta Helburuaren arteko distantzia alde batetik, eta Sorburu eta Helburu guneetako item lexikalaren errepikapena bestetik. Parametro horiek beste honi, alegia kultura eta testuinguruko informazioaren funtzio pragmatikoari, askotu behar zaizkio. Askotze horrek elkarreragiketa dakar eta elkarreragiketa horiek guztiak hartu eta beharrezkoak direnak bakarrik hautatuko dituen azalpen ereduren bat behar dugu. Eredu hori Turner eta Fauconnierren Kontzeptu Baterakuntzaren edo Nahasketaren Teoria da. ${ }^{27}$

\footnotetext{
24 Gogora ekar dezagun RSko 29. atsotitz hura denboraren balorazio kultural baterako : "aldi txaburra lasterra bada, egun astia baino hobe da". Lakarra 1996.

25 Ikus Fauconnier eta Turner (2002) lehen aipatu compression/decompression kontzeptuak.

26 Hori parez pare doa Kayk deskribatutako ingelesezko hedges edo jostura horien azterketan ondorioztatutakoarekin (cf. "strictly speaking").
}

27 Fauconnier eta Tumer (1994, 1996, 1998, 2001, 2002) eta Turner eta Fauconnier (1995) 


\subsection{Kontzeptu Baterakuntza}

Bateraketa kontzeptuala gogo-espazio diferenteen arteko sareak sortzen dituen oinarriko gogo eragiketa da 28 . Espaziook sarrera espazio gisa joka dezakete, beste espazio berri bateratu baterako. Nahasketa espazioaren ezaugarrietako bat hauxe da : sarrera espazioetan ez dagoen egitura berria eta diferentea azalera daitekeela bertan.

Oinarriko gogo-eragiketa horren abantailetako bat izan daiteke, ekintza eta pentsamenduaren hainbat esparruri aplika dakiokeela, baita gramatikaren esparruari ere. Gramatikan antzoki (scenario) abstraktu batzuk dagozkien egitura gramatikalen bitartez errepresentatzen dira eta egitura dagokion antzoki eskematikoarekin batera dator. Gertaerak delako egitura hori erabiliaz deskribatzean, entzuleari gertaera horiek antzoki eskematiko horretan batera ditzala eskatuko zaio. Era horretara, "nahasketa" gramatikaren jarduera funtsezkoa da ${ }^{29}$. Teoriaren aldetik hemen dagoen jauzia hauxe $\mathrm{da}$, formaren bitartez mundua azaldu nahi duten diziplinen kontra, hemen antzokiaren bitartez egoeraz ari garela, eta egoera horrek bat egingo duela eskema formal batekin, zeinetan burutzeko zirrikituak dauden. Hola gramatika egoeraren atzetik doa, hots. formak ez dakar esangurarik baizik eta esangura eraikitzeko aginduak eta aztarrenak eman.

BOEk bidearen antzoki abstraktua ekarriko digu gogora, Kayren eskemata balitz bezala ${ }^{30}$. Antzoki honek arestian aipatu ditugun osagaiak bateratzeko behar den sare kontzeptuala emango digu, hala nola, (1) BOEren esangura bera, (2) parametro biak, (3) item lexikalen arteko harremana - harremanok lituzketen inplikazio metaforikoak barne, hau da,

\footnotetext{
$\overline{28}$ Teoria hori luzeago eta sakonago azalduta dago Garai 2002 eta 2003etan. Bada euskalari itzal handiko bat, Juan Gartzia, gogo-espazioak "mundu posibleekin" nahasten dituena, baina ez duenez erreferentzia argi esaten, ezin izan diot inoiz aurrez aurre zuzendu; Leioan 2001ean egin zen Terminologia Kongresuan hala iruditu zitzaidan, eta berdin gero Itzulist bezalako foroetan gai hau erdi atera denetan. "Mundu posibleak" modalitatearen arazoa eta existentziazko erakusle "unibertsalak" argitzeko sortu zen, nolabait sistema Fregearraren adinontze bat da (ikus Hornstein 1995 praktikotasunaren izenean, Tarskiren konplexutasunaren aurkako Fregeren sistemaren soilaren aldeko jarrera baterako); Aldiz, gogo-espazioak esangura fardelak dira, maila lokalean eraikitzen direnak; alde horretatik gramatikak aginduko digu zein espazio eraiki behar dugun, eta zein den espazioon artean ezarri behar dugun lokarria. Ez dute beraz bat ere zerikusirik. Sakonago Fauconnierrek berak azaltzen du Mental Spaces 1985 MIT. Intelektualak sofistikazio eskakizuna du (sofistikazioa etimologikoki hartuta : ikus Gerald M. Phillips et al. Survival in the Academy : a guide for beginning academics. SCA Applied communication publication program. Cresskill, NJ : Hampton press, 1994.), eta horrek esan nahi du teoriaren aurrerakadei ezin zaiela muzin egin, I. Sarasolak publikoki askotan esan ohi duenaren kontrara.
}

29 Paragrafo honetan oso hurbil jarraitu gatzaizkio Fauconnier eta Turner 2001.

30 Kay $1997: 202-203$. 
batzuk Oinarriko Metafora Kontzeptualak lirateke, bitzuk kultura horrek duen gorputzaren kontzeptualizazioan sartuko lirateke, eta bestetzuk lotura pragmatikoek murrizturikoak izango lirateke — eta (4) testuinguruko informazioa. Hori guztia Fauconnier eta Turnerren Kontzeptu Bateraketa teoriaren arabera ematen saiatuko gara, hala gogo-espazioen konfigurazio proposamena ere emango baitugu.

\subsection{Gogo-espazioen konfigurazioa}

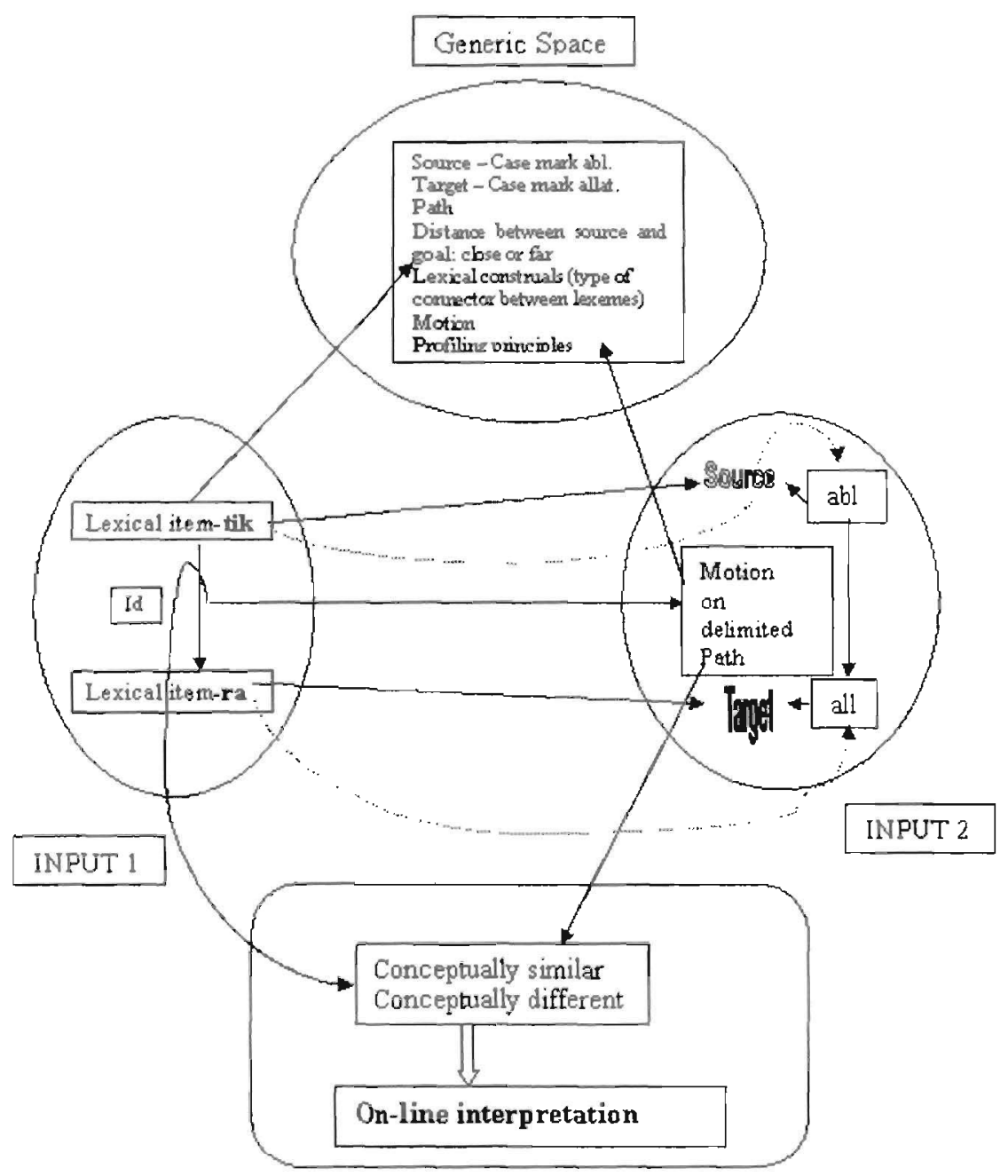

BLEND 


\section{Sarrera espazio 1 (input 1) :}

Espazio honetan, hizkuntza zatikia bera izango dugu, emaitza den aldetik. Item lexikalen arteko erlazioa identitate konektorea edo lokarria da; Lokarriak emango digu distantziaren gaineko informazioa.

\section{Sarrera espazio 2 (input 2) :}

Egitura abstraktua ez idiomatikoa egongo da gogo-espazio honetan. Egitura horrek faktore hauexek ditu : BOE, Deklinabide atzizkiek ematen dutena, Sorburu eta Helburu rolak, Atzizkiek rolekin duten lotura, eta Bide batetiko higidura.

\section{Espazio Orokorra (Generic Space) :}

Sarrera espazio biotatiko informazioaren hezurdura edo oholtza orokorra egongo da espazio honetan; hau da, Sorburuak eta ablatiboak, alde batetik eta Helburuak eta adlatiboak bestetik luketena; halaber, Bidearen antzokiaren oholtza, bai eta Sorburutik Helbururako distantzia ere, zehatzago, hurbiltasunak antzekotasuna dakarrela eta urruntasunak bestelakotasuna. Egituraketa lexikala ere espazio honetan gertatuko da (item lexikalen arteko lokarri mota), Mugimendua bera eta nabarmentze hatsarreak ere bai.

\section{Bateraketa Espazioa (Blend) :}

Hemen interpretazioa online suertatuko da, lekuan-lekuan eta lekuan lekuko. Zelanbait esan, espazio orokorrean genituen posibilitateak input espazioek murriztuko digute, eta hala bere eskuko egitura sortuko zaigu nahasketa espazio honetan; adibidez, lehenago emandako tipologiaren hautaketa gertatuko da espazio honetan, edota lehen aipatu nabarmentze edo profiling printzipioek jokatuko dute hemen. Erabilera idiomatikoa denean, nahasketa honetako emaitza berriro proiektatuko da bigarren inputera, eta egitura abstraktuari erantsiko zaio esangura idiomatikoa, eta abar.

\section{Ondorioak}

Azkenik saiatuko gara gure ondorio gehienak hurren ematen. Argi dago gure ekarririk handiena egitura beraren aurkikuntza izan dela, bai eta egituraren 'ubikuotasuna'edo 'perbasibotasuna'; bestela esan, ez dela kasualitatea hainbestetan agertzea hizkuntzan.

Beraz, BOE 'egitura'bat da, euskaraz oso emankorra eta semantikoki aberatsa, haren esanahia 'bide hesitua'da. Eredu integratzaile baten proposamenerako bi parametro eman ditugu : Sorburuaren eta Helburuaren arteko distantzia, eta Sorburu eta helburu lekuetako item lexikalaren errepikapena. Eredu 
integratzaile horretan elkarreragiketa dakarten faktoreak hauexek dira : item lexikalen eduki semantikoa, alde batetik, eta, bestetik, eredu kulturaleko eta testuinguruko informazioaren funtzio pragmatikoa. Elkarreragiketa horien funtzionamendua eta erabilera saiatu gara argitzen Turner eta Fauconnierren 'Bateraketa Kontzeptualaren'edo 'Nahasketaren teoriaren'argitan.

Egiteke zenbait gauza geratu zaizkigu, adibidez, esapideen esamoldezkotasunaren maila; egin dezagun, zein da hitzetik hortzera vs. gezurretik gezurrera dagoen aldea? Nola egin horretarako mailakatze edo graduazioa? Egitekoen arteko beste bat item lexikalen barne egitura eta harremanak zehaztea litzateke, hau da, ahotik eskura esamoldean metonimiak hartuko luke parte, baina kukutik kukura esamoldean ezagutza kulturala behar da jakiteko kukuak noiz kantatzen duen eta zelan lotzen zaion kukuaren kantua zoriari; hori eredu kulturala baino zertxobait gehiago da. Azkenik, BOEren emankortasuna esapide berrietan ere aztertu beharko litzateke, egituraren malgutasun sortzailea neurtzeko, eta horrekin lotuta, zein den 'nondik nora'egiturak 'zerez nora'bezalakoekin duen zerikusi semantikoa.

Artikulu hau Ibarretxek eta Garaik darabilten egitasmo zabalago baten zati bat baino ez da, baina duda gabe azterbide oso bat dago hemen sartuta; bazterrekotzat edo periferikotzat jotzen ziren egitura eta esamoldeak hizkuntzaren muineko gramatikari dagozkiola erakusten du azterbide horrek, hain zuzen, LEFek aztertu hitz konposizioan euskararen gramatika osoa sartzen den bezalaxe.

Hurren heldu dena gure korpuseko adibidetegia da.

\section{Adibideak}

\subsection{Gorputz, atalak}

Hitz neurtuak kantuz zortzikoan edo beste edozein neurritan, supituan ahotik ahora elkarri ematea.

- Ahotik belarrira zuek gelan erasia' etxe-gainetik oihu egingo dute.

- Ahotik hortzera ez dira elkarrez fidatzen

-Ahotik sudurrerainoko astirik gabe

- Ahotik ukabilera berehala dute sarrera mutil biak, lagunek berezi dituzten arte

- Neure aulki polita besotik behera dudala banoa elizara

- Hitza gogotik mihira

- Mingainetik hortzera baino lehen gezurra

- Honetan, hitzetik hortzera hara non azaltzen den Santa Krutz Berrobin

- Burutik orporainoko larrua erabat kentzera lehenago jarriko liratekeela nago, hori aitortzea baino 
- Etxetik eramañ zen, eta etxera dator : kolkotik magalera erortzea egin du

- Ez du sudurretik ahorainoko astirik

- Sudurretik ahora ez daki edukitzen (ez daki deus ere isilik edukitzen)

\subsection{Denbora, eguna, astronomia}

- Erran, no, Katalin : diru puska bat norbaitekin jokatu dinat bi lagunekin husten ditunala ehun pinta arno, argitik argira, hiri zer zaun?

- Argitik iluneraino eguna daramat bihotz onez lanean

- Atzotik gaurrera hau da geure plazaren itxura bakana! Azoka honek dauka ematen dioten beste ospe?

- Arta-jalkitzen aria duzu Mikela bazkaltzetik afaltzera

- Ohe eder garbia jarri zioten Joanesi Azkarragan, baina ezin zuen ezertara lorik erakarri : esna eta larri zegoen behingotik behingora buru, hanka eta besoak harantz eta honantz aldatuaz

- Berandutik berandura eta bortxaz bezala Sakramentu hau hartzen dutenak

- Bakarra naiz; ez da nitaz bertze Jainkorik; ni naiz bizi naizena, betitik betira

- Egunetik egunera ezagutzen zitzaion atzeneko arnasakaz zebilela...

- Ohitura txar hau daukanak egunetik egunera txurrutera jotzen du

- Eguzkitik eguxkira eta izerdi patsetan behar egiten dute askotan

- Gauetik egunerakoa ezagun dute nola altxatuak diren eskolan bi haurrideak

- Uralde izugarri bat jaitsi da bihuri, eta herri ederra txikitua du gauetik goizera

- Elizarik txikienean ere urtearen goienetik barrenera gutxienez ehun bider entzuten da kanta hau

- Etxe bazterrak zilar eduki zituen beti, goizetik arratsera

- Goizetik gauerakoan Erregeren alaba zaharrenagaz ezkondu zuten

- Hauxe zen eguneroko jarduera : aztarrika batean goizetik gauera

- Hurbiletik hurbilera erdietsi du nahi zuena

- Harik gehiago ez ei dute irten laminek, eta honela hurrengotik hurrengora hondatu eta egundo gehiago ez ei da izan euren berririk

- Igandetik astelehenera bada gaua.

- Noiztik nora egin zara zu sermolari?

- Noiztik nora iraungo du gure kontratuak

- Zaharrenetik zaharrenera jarrita zeuden

- Urtetik urtera gauza gora joaten da, jornal gutxia ematen da : Langile denak belarra jatera gatoz

- Kukutik kukura joan ohi gara; urtetik urtera 


\subsection{Espazioa eta lekuak}

- Zotin gogor eginda, arnasa atzetik aurrera jiratuaz hona zer erantzun zidan gaixo hark

- Harria jo arte badoa ur hori azaletik barrurantz

- Bazterretik bazterrera inarrosia da hiria

- Mendiak behetik gora hankak jaso zitik erbiak zakurrak atzetik dituela

- Ikusten duk, arropa-zorroa bizkarrean duela, behetik gora itoka eta lehertzeko zorian datorren gizon hori?

- Hori behetik gora janzten da. "Es un afeminado" sic.

- Piperrak behetik gora jotzen dit/Lukainkak behetik gora jotzen nau

- Behiaren marrua entzun orduko etxea jasoko du behetik gora gure gizonak

- Gure eskolaren luze eta zabaleko neurriak berdinak dira ; behetik gorakoa lau kana

- Bere moduko mutil batzuek hogeita hamaikarena eginaz gure bidetik aurrera joan ziren

- Ondo eusten ez badiogu euskarari azkar eta laster goaz gailurretik behera

- Nahigabe batek alde egin ez ahal du ustekabeko beste asko datoz gainetik behera

- Plazaren goienetik barreneraino

- Gizon handi horiek santuak ziren, baina goietatik behetara jaitsi gaitezen.

- Hartu zuen bere eskuetan albistaria Mañasik eta arnas batean goitik barreneraino begiratu zion

- Goitik behera destainaz begiratzen diozue

- Zoroekin bigunean ezin liteke... Haserretzen denean goitik behera eman, erruki barik

- Gaztetako kontuak bertan behera utzi! Bestela beharko duk goitik behera jaitsi (arruinarse)

- Goitik beherako ur biziak azpia jaten dionean nork eutsi etxe horri erortzeke?

- Zer darabilzu handikotik hortikora?

- Gure herriak ezin izango luke inondik inora bururik atera

- Txinelak ahalegin guztiak egin arren inondik inora ezin topatu dute non dabilen gizon hori

- Nahikoa da lau-bosten bat hatz lur, sustraia hasten den lekutik gora

- Mailatik mailara amilduaz doa behin adin batera ezkero.

- Bere burua nondik nora agertuko zuen zebilen

- Nondik nora asmatu duk okerkeria hori

- Nondik nora da Euskalerria?

- Hori ez dakigu nondik nora den

- Gauza horien sustraia nondik nora zetorren ikusirik nori bere eskubidea gordeko zitzaion

- Hobetoago beharrez ari natzaizu ; zerorrek pentsa nondik nora ateak jo 
- Horra zenbat arazeria eta zenbat oker datozkien tabernatik tabernara dabiltzan nekazari gaixoei

- Guziei zegokien donario ederrean zihoazen, hodeia nora haiek hara, tokitik tokira atsedentxoak egiten zituztela

- Urteroko garai jakinetan, urrutietatik urrutietara hegazti-alde askok egiten duten bazter aldaketa.

- Zalditik astora eta astotik lurrera dabiltza

- Zertik zertara haserretu ziren?

- Zertatik zertara jauzten ziren bada (qué manera de pasar de un asunto a otro)

\subsection{Ekintza sinbolikoa eta epistemikoa}

- Eskritura Santuko esanak ez dira betiere berbatik berbara euskarara bihurtu liburu honetan

- Nagusiagaz berbatu zen, eta berbetatik orroetara jo zuten, eta orroetatik ukabiletara

- Eletik elera hau erraten zigun (a cada palabra)

- Euskararen erabiltzetik erabiltzera bide handia izan daitekeela eta badela inork ez dezake uka

- Esanetik eginera bitarte luzea omen dago; hemen-halere esatea eta egitea bat bera dira

- Ezetik baiera asko (Deus ez denean zerbait duenak asko du)

- Alperrik duzu horiei galdetzea : ezetik baiera daude (están a la cuarta pregunta)

- Zergaratik zergarara etortzen zen (De tiempo en tiempo)

\subsection{Posposizioak, Deixis antropozentrikoa}

\subsubsection{Norabiderako egiturak}

- Hemendik... post.ra (Honetik... post.ra) : Hemendik aldera, hemendik aurrera (honetik aurrera), hemendik gora, hemendik hara

- Hortik... post.ra (Horretatik... post.ra) : Hortik aurrera, Horretatik aurrera, Hortik behera, Hortik hona, horretatik hona, Hortik horra, hortik kanpora

- Handik... post.ra, (Hartatik... post.ra) : Handik aurrera (Hartatik aurrera), Handik aztura, Handik behera, Handik behera, Handik gerora, Handik gora, Handik hara (Hartatik hara), Handik hona, Handik inora, Handik lekora, Handik kanpora, Handik ingurura; Handik hilabetera, Handik lasterrera, Handik luzarora, Handik oraindaino, Handik ordu erdira, Handik puntura, Handik zortziurrenera

- Lex. tik... posp.ra : Tik albora, tik aldera, tik atera, tik aurrera, tik barrenera, tik behera, tik gehiagora, tik gora, tik hara, tik hona, tik hurrera, tik inora, tik kanpora, tik lekora : "Auzitik lekora bat atorra has, bertzea biluzgorri ardura". 


\subsubsection{Espazio izenordeen kasu berezia}

- Bat... tik Beste... ra : Batekotik bestera, Batetik bestera, Batzuetatik besteetara

- Beste... tik beste... ra : Bestekotik bestekora, Bestetik bestera

- Tik beste... ra : Hemendikotik bestekora, tik bestera

\section{Bibliografia}

Berman, Ruth A., eta Dan I. Slobin. 1994. Relating events in narrative : A crosslinguistic, developmental study. Hillsdale, NJ : Lawrence Erlbaum Associates.

Cacciari Cristina eta Patrizia Tabossi (arg.). 1993. Idioms : Processing, Structure, and Interpretation. New Jersey : Lawrence Erlbaum Associates.

Fauconnier, Gilles eta Mark Turner. 1994, Apirila. "Conceptual Projection and Middle Spaces." UCSD Department of Cognitive Science Technical Report 9401.

Fauconnier, Gilles eta Mark Turner. 1996. "Blending as a Central Process of Grammar." In : Adele E. Goldberg, (arg). Conceptual Structure, Discourse, and Language. Stanford : Center for the Study of Language and Information (CSLD), distributed by Cambridge University Press. 113-129. Sareko bertsio

ugaritua

URL

http://www.wam.umd.edu/ mturn/WWW/centralprocess/www/centralprocess.html.

Fauconnier, Gilles eta Mark Turner. 2001. "Conceptual Integration Networks" (Expanded web version, 10 February 2001). URL : http://www.inform.umd.edu/EdRes/Colleges/ARHU/Depts/English/englfac/MTurner/cin.web/cin.html. Berreditatua hemendik : Cognitive Science, 22 (2) 1998, 133-187.

Fauconnier, Gilles eta Mark Turner. 2002. The Way We Think : Conceptual Blending and the Mind's Hidden Complexities. Basic. New York : Books (Perseus Books).

Fauconnier, Gilles. 1985 1994. Mental Spaces : Aspects of Meaning Construction in Natural Language. Cambridge : Cambridge University Press.

Fauconnier, Gilles. 1997. Mapping in Thought and Language. Cambridge : Cambridge University Press. 
Fillmore, Charles J; Kay, Paul eta Mary Catherine O'Connor. 1988. "Regularity and Idiomaticity in Grammatical Constructions : The Case of Let Alone." Language. 64, 3, Sept, 501-538.

Garai, Koldo J. 2002. "Limurketa eta Esanguraren arteko Harremanak euskal Atsotitzetan." Gogoa. II-2 : 227-287.

Garai, Koldo J., 2003. "Esanguraren eraikuntza euskal atsotitzetan : linguistika kognitiboaren ekarria literaturaren azterketarako". Iker, 14. II, 89-111 orr.

Garai, Koldo J., 2004. “Gogoaz eta Hizkera figuratuzkoaz zenbait apunte : Gogo hizkuntzalaritzako ekarri batzuen gainean" Argitaratugabea.

Garai, Koldo J., eta Iraide Ibarretxe-Antuñano. 2002. "From x to $y$ : the "complete path'construction in Basque. Anders Hougaard \& Steffen Nordahl Lund (arg.). The Way We Think: Odense Working Papers in Language and Communication 23. August 2002.

Goldberg, Adele E. 1995. Constructions : A Construction Grammar Approach to Argument Structure. Chicago : University of Chicago Press.

Hornstein, Norbert. 1995. Linguistics and philosophy. 18, no. 4, (1995) : 381. Dordrecht Boston: D. Reidel Pub. Co.

Ibarretxe, I. 2003. "Path in Basque". 8th International Cognitive Linguistics Conference. Errioxako Unibertsitatean aurkeztutako txostena.

Ibarretxe, I. 2004. "Motion events in Basque narratives". Sven Strömqvist eta Ludo Verhoeven (arg.) Relating events in narrative: Typological and contextual perspectives. Hillsdale, NJ : Lawrence Erlbaum, 89-111.

Ibarretxe, I. Arg.1. Language typologies in our language use : the case of Basque motion events in adult oral narratives. Cognitive Linguistics.

Ibarretxe, I. Arg.2. Basque : Verb-framed or sateliite-framed? Linguistic Typology.

Izagirre, Koldo. 1981. Euskal Lokuzioak. Donostia : Hordago.

Kay, Paul. 1983. "Linguistic Competence and Folk Theories of Language :

Two English Hedges." In : Paul Kay Words and the Grammar of Context. Stanford : CSLI lecture notes.1997.

Kay, Paul. 1987. "Three Properties of the Ideal Reader.". In : Words and the Grammar of Context. Stanford : CSLI lecture notes. 1997 : 203. 
Kay, Paul. 1997. Words and the Grammar of Context. Stanford (Ca) : CSLI Publications.

Lakarra, Joseba A (arg.). 1996. Refranes y Sentencias (1596): Ikerketa eta Edizioa. Bilbao : Euskaltzaindia.

Lakoff, George and Mark Turner. 1989. More than Cool Reason : A Field Guide to Poetic Metaphor. Chicago : Chicago UP.

Mayer, Mercer. 1969. Frog, where are you? New York : Dial Press.

Mokoroa, Justo M. 1998. Ortik eta emendik. Herri euskarako esamolde bilduma/Repertorio de locuciones del habla popular vasca. CD-ROM. Hiztegiak eta Gramatika gaiak. Labayru-IVAP.

Mokoroa, Justo Ma . 1990. "Ortik eta emendik". Repertorio de locuciones del habla popular vasca (I eta II). Labayru-Eusko Jaurlaritza.

Slobin, D. I. 1996b. "Two ways to travel: Verbs of motion in English and Spanish". In M. Shibatani \& S. A. Thompson (Eds.), "Essays in semantics". Oxford : Oxford University Press, pp. 195-317.

Slobin, Dan I. eta Nini Hoiting. 1994. Reference to movement in spoken and signed languages : Typological considerations. Eskuizkribua, argitaragabea.

Slobin, Dan Isaac et al. 1996. Social interaction, social context, and language : essays in honor of Susan Ervin-Tripp. Mahwah, NJ : Lawrence Erlbaum Associates.

Talmy, L. 1991. 'Path to realization : A typology of event conflation'. Proceedings of the Seventeenth Annual Meeting of the Berkeley Linguistics Society, pp. 480-519.

Talmy, Leonard, 1978. "The Relation of Grammar to Cognition - a Synopsis." In Waltz, David (arg.), Proceedings of TINLAP-2. New York : Association for Computing Machinery, pp. 14-24.

Talmy, Leonard. 1985. "Lexicalization patterns : Semantic structure in lexical forms." In : T. Shopen (arg.). Language typology and semantic description : Vol. 3. Grammatical categories and the lexicon. (36-149 orr.). Cambridge, UK : Cambridge University Press.

Talmy, Leonard. 1995. "Fictive Motion in Language and "Ception"." In : Paul Bloom, Mary Peterson, Lynn Nadel, eta Merrill Garrett (arg.). Language and Space. (307-385 orr.) Cambridge, Mass. : MIT Press.

Talmy, Leonard. 2000. Toward a Cognitive Semantics. 2 vols. Vol. 2, Language, Speech, and Communication. Cambridge, Mass. : MIT Press. 
Turner, Mark eta Gilles Fauconnier. 1995. "Conceptual Integration and Formal Expression." URL : http://www.uoregon.edu/ rohrer/tumer.htm Accession : 2/16/99. Mark Johnson (arg.), Journal of Metaphor and Symbolic Activity. 10, 3.

Turner, Mark. 1996. The Literary Mind. New York-Oxford, Oxford University Press.

Zamarripa, Pablo. 1913. Manual del vascófilo. Bilbao : Wilsen editorial, edizio fotografikoa. 1987. 